Constantin Vică

\title{
10 The Info-Computational Turn in Bioethics
}

\subsection{All watched over by machines of loving grace?}

In 1967, one of the most eccentric American writers, Richard Brautigan, wrote a visionary poem about the future of our species in a cybernetic world:

I like to think (and/the sooner the better!)/of a cybernetic meadow/where mammals and computers/live together in mutually/programming harmony like pure water/touching clear sky. [...] I like to think/(it has to be!)/of a cybernetic ecology/where we are free of our labors/and joined back to nature,/returned to our mammal/brothers and sisters,/and all watched over/by machines of loving grace.

This visionary poem was revived in a British Broadcasting Corporation (BBC) documentary by Adam Curtis because it encompasses our deepest expectations, hopes, and fears about living in a digital realm, a way of life that is becoming increasingly dystopian.

It took a long time for us to accept that we are evolved natural automata, i.e., nondeterministic but probabilistic organisms. Perhaps this idea of human beings lacks what many of us hold to be one of the most important characteristics of humanity: we are not mindless creatures but cultural beings capable of developing our own consciousness through time. We self-define as being part of a unique category that transcends the limits of the natural. Still, this intellectual reality we impose above nature is not very helpful when we encounter other artificial kinds.

Bioethics as a field is diverse and complex enough to escape from precise taxonomies. Although it is a perpetual activity of finding purpose, criteria, and justifications, the bioethical discourse can be understood or appraised in numerical terms. This is the reason why this blend of medical thinking and practical ethics, this combination of empirical and normative dimensions, gets much closer to computability (i.e., algorithmic treatment of information and knowledge) than practical philosophy alone. An info-computational perspective in bioethics opens the possibility that moral subjects should not be necessarily understood as biological entities before ascribing their metaphysical, epistemological, and moral status.

I plead at large that research and practice in medical ethics and bioethics should take into account the convergence of computing, information, and life, i.e., the convergence of artificial and natural kinds, into a single new technological 
lifeworld (Ihde 1990; Mitcham 2014, 25)1 ${ }^{1}$ Otherwise, the moral human agent and patient will be lost from sight and will become incomprehensible. The human being must be reaffirmed in a different manner than before: medicine and health care are becoming progressively "infocentric", ${ }^{2}$ and this change entails a conceptual shift in what makes a human a person (and a change in the relationship of agency, duties, environment, and therapy). The last decade created the foundation for a myriad of new technologies now used in day-to-day medicine, health-care practices, and biomedical research. The development in bioinformatics made gene sequencing and editing technologies, such as clustered regularly interspaced short palindromic repeats (CRISPR)/CRISPR-associated proteins (Cas) 9, possible. Large sets of data, including genomic data, and algorithmic analysis, i.e., Big Data, open the way for new insights into both pharmaceutical research and medical practice. Automation of health care through intelligent assistive technologies is on the rise (Ienca et al. 2016; 2017). Nonetheless, the Internet is a medium for telemedicine and self-medicine: more and more people get their health information online, and this behavior is producing huge amounts of data ${ }^{3}$. The quantified-self movement, based on applications that monitor body functions and status, produces a variety of "small' medical data (Swan 2013), while virtual reality environments create possibilities for medical training and therapy (Opriş et al. 2012). This technological setting generates, in the words of James Moor, “policy vacuums and conceptual muddles" (Moor 2008, 34). I believe we cannot cope with them by turning to the mainstream theoretical view of agency in bioethics. Why?

The impact of these technologies on the bioethics framework of thinking will be radical and essential, rather than limited and contingent. Bioethics was structured as a field of inquiry mainly about natural beings and biological life ${ }^{4}$ - bodies and minds, their moralities and policies - but the "fourth revolution" (Floridi 2014) introduces new entities and processes into this field of inquiry. What is different about this informational revolution resides first of all in its capacity to penetrate human life as a whole; it spreads regardless of any cultural differences or social structures. Secondly, it is irreversible in its impact. Until now, bioethics has produced a corpus of knowledge based on ethical theories that were mainly focused on human agents

1 Moral foundations and actual methods of bioethics are not prepared for the task of understanding this novel way of doing medical science and providing health care (which has also large consequences for future politics and economy).

2 The quotation marks used here want to raise a doubt about the general accepted meaning of this term. I will explain my own use in the third section.

3 An exhaustive survey conducted by the European Union in 2014 established that six out of ten Europeans went online looking for health information: https://ec.europa.eu/digital-single-market/en/ news/europeans-becoming-enthusiastic-users-online-health-information (accessed on May 12, 2017). 4 Or, at least, since the concept of "person" was extended to nonhumans, such as dolphins, chimps, bonobos, or elephants. 
and living subjects, as one can see in the taxonomy proposed by Arras (2016). New digital technologies swing the focus from the human agent to an efficient treatment of information (for many purposes), something that is part of the posthuman condition. This being the case, the fundamentals of bioethics (e.g., the principles of care and compassion) are at odds with an infocentric doctrine. Moreover, the privilege of human agency in moral decision-making presupposes a different conception of attention, time, and persons than infocentrism, a doctrine based on the assumption that everything can be reduced to data and information. Hence, the question we have to answer is this: is it possible to approach this shift from the "traditional" or "canonical" understanding of agency provided by bioethics? If not, what is to be done in a world of shared agency with artificial kinds?

\subsection{The digital epidemiology}

Viruses and ideas can spread within a population in a matter of days or weeks. It is enough to have a set of nodes and connections proportionally distributed within that group. In this section, I explore the contemporary digital setting and its properties, keeping with the metaphor of contagious viruses. Moreover, I explain why the changes made possible by this setting are radical.

Algorithms, neural networks, digital codes, digital data, and even digital semantic information are not merely objects to be handled in a neutral way. They are encapsulated in computational processes; they act as a technology based on languages and logical operations, able to alter not only information but also human perception, cognition, and beliefs. It is better to think of them as a clique of causal and powerful tools-as-features, and at the same time, as human extensions and environments of our experience (McLuhan 1994). As mediums of our human experience, they also convey the means for understanding it. We act both through them and according to them. The problem of agency is stringent: are they mere functional instruments "in our hands” or are we all together forming a joint apparatus (Introna 2014)?

Hopefully, the term "setting" is not used in an arbitrary manner: digital forces set guidelines for inquiry, knowledge, and affordances for action. They set the modes of our existence, generating not only the places but also the rhythms of experience. Their permeation of the social world is a cold fact - if we acknowledge that $>3.5$ billion people are online and half of them are on Facebook ${ }^{5}$ - and their pace of pervasion is on the rise. In other words, the artificial digital realm is spreading like a virus. However, a biological virus is not bad in itself, as it can occasionally alter our DNA: around $8 \%$ of human genetic material originates in viruses, and retroviruses and

5 For other figures in real time, one can access the Internet Live Stats website: http://www.internetlivestats.com (accessed on March 27, 2017). 
bornaviruses play a role through endogenization in the reproductive success of our species (Feschotte 2010; Horie et al. 2010) In the same way, a cultural "meme" or "virus" can link human minds for the greater good: new conceptions of freedom, equality, solidarity, and justice are historical facts and their disseminative action was a virus-like process. Still, this exploit could change not only the fundamental structures of life (as bioinformatics has already transformed biology and medicine into information sciences, everything is possible when tinkering with life) but also our intellectual conceptions of it.

In order to determine why the info-computational shift is so substantial and irreversible, we have to take a step back and get a bird's-eye view of the general purposes of these digital technologies. A first characteristic is their capacity to be transformative: digital innovation is incremental and cumulative, inasmuch as it frequently changes the forms of perception, mental states, social relations, and general welfare. For example, algorithms not only metamorphose data into new information but also alter the manner in which humans process their increasingly computational environment (Voinea 2016, 592-594).

Transformation does not come alone; it has a companion: pervasiveness. Pervasive or ubiquitous computing is not limited to what is visible to persons, as in the case of our desktop computers and laptops. Computation and data processes are now everywhere, from wearables and home appliances to cars, planes, hospitals, and supercomputers. Perhaps the best way to understand this change is to witness the technological subrevolution of smartphones and realize how these tools have transformed all of us into agents in social media. The next such revolution will be accomplished through brain-computer interfaces, especially in medicine (Wolpaw et al. 2002, 786-7).

Secondly, the digital realm is emergent and generative: its properties are constantly changing, and its aggregation into new formulas is impossible to predict. The idea of generativity within information systems is especially important because it valorizes individual freedom of choice, while also reminding us that we should not completely trust our forecasting capacity. To be generative means to be capable of producing "unanticipated change through unfiltered contributions from broad and varied audiences" (Zittrain 2008, 70). This is exactly what the Internet has done: these technologies can be leveraged because they are versatile enough to meet almost any task. It is easier to use them than to use almost any other tool because of their accessibility (Zittrain 2008, 71-3). All this time, we were not able to predict any of the changes happening within our online empire. We did not guess anything about the rapid rise of Facebook or about hacking politics through "computational propaganda" in 2016 (Woolley and Howard 2016). Expecting the unexpected seems to be the rule of the game.

The third much-admired virtue of information and computer technology is its effectiveness. These technologies are the most powerful tools we have ever had for treating huge amounts of data in a limited amount of time. Their success in 
accompanying humans in economic and social tasks is historically outstanding. This efficacy creates folklores about computers and algorithms being all-problem-solving engines and also raises the hope of liberating humans from their burdens. Indeed, digital tools are more efficient than analogue ones simply because they work with discrete entities, i.e., numerical values that can be perfectly replicated without any loss of information or structure. In fact, if we can convert them to newer formats, these objects are not only placeless, but also timeless. The equivalence of type and token in the case of digital information processing makes them perfect candidates for eternal endurance without the degradation inherent to analogue objects. They are the Cartesian and Leibnizian dream of precision, exactitude, and universality, but there is a weakness. Computation, algorithms, neural networks, software, and digital hardware are prone to errors. Error is a part of the technological condition of these particular artifacts, as well as of any kind of technology. In an era of ubiquitous computing, we cannot always detect deep errors, but only some of the visible glitches. A broken hammer is the image Heidegger $(1962,98)$ related to and used for explaining the essence of technology, but in our case, the situation is quite different as we cannot even know when the tool is wrecked. Although a digital tool is, in a Heideggerian jargon, "ready-to-hand", it is not always apparent when it "breaks". Resembling fine exploits, errors can pass undetected for a long period. They can also create a cascade of errors that can disrupt, for instance, the activity of an entire hospital within seconds ${ }^{6}$. The opacity of digital objects - even the open source ones - is frightening since they can be socially disruptive.

The digital setting is almost comprehensive and complete in creating the new technological lifeworld, at least for half of the Earth's population. The viruses of digitalized society and the digitization of life - two different manners of the expansion of the digital realm -are spreading fast because they help us survive. The difficulty resides in understanding that we have changed not only the setting for life but also the artificial ambient that we interact and coevolve with. Everything is now computable because it can be expressed as data. In this setting, thinking about the uniqueness of human agency and its mastery over the world and life without accepting the causal effectiveness, generativity, and pervasiveness of the artificial kinds is doomed to miss the point, leading to its irrelevance, despite its moral value. To explain how to avoid it, I will sketch an alternative view to the "traditional" assumptions in bioethics related to life, objects, and agency.

6 In the making of this article, a case of hospital cyber security lapse emerged in the UK. The National Health Service (NHS) was attacked by the 'WannaCry' ransomware. For more information, follow The Guardian link: https://www.theguardian.com/society/2017/may/12/hospitals-across-england-hit-bylarge-scale-cyber-attack (accessed on May 13, 2017). 


\subsection{Ways of understanding the info-computational turn}

Three categories could help us decipher the info-computational turn examined above: logical malleability, infocentrism, and secondary agency. These concepts should also inform an alternate view in bioethics. What I have called an inadequate mainstream approach in bioethics (within the digital setting of our technological lifeworld) is shaped by assumptions about normativity, human agency, and universality of moral judgment (Zylinska 2009, 9). Zylinska (2009, 4-11) recognizes the following assumptions within mainstream bioethics: normativity is "predefined" by a specific idea of the good, agency resides solely in human rational subjectivity, and there is continuous demand for universalization of judgments even when it comes to particular cases and their substantial differences. I do not endorse her ensuing critique and positive proposal, but I believe the "diagnosis" is appropriate.

Logical malleability is the main capability that computers have. As James Moor (1985), one of the founding fathers of computer ethics, puts it: "Computers are logically malleable machines in that they can be shaped to do any task that one can design, train, or evolve them to do". Moor $(2008,35)$ highlights two levels of this capability: the syntactic one - because computers are able to process numbers by a multitude of logical operations - and the semantic one - the capacity to represent "anything we wish" through numerical values and logical states. Without a doubt, semantic malleability is revolutionary in the sense that information processes could be used to represent, model, virtualize, and simulate phenomena, hence producing "a materialization of our conceptual knowledge of the world" (Dodig-Crnkovic 2004, 3). Computers are "universal tools" (Moor 2008, 35), adaptable to tasks that were impossible for other tools. One consequence of this malleability is the incessant novelty and the lack of predictability that accompanies the use of computers and networks. Difficulties produced by the unexpected possibilities of computing are evident in the case of creating information ethics policies. These policies could only approximate our present concerns, so they must continuously adjust to the new problems we encounter (Moor 1999, 68). Thus, it is increasingly difficult to substantiate ethical guidelines or an idea of normativity in an aprioristic manner, beyond actual experience; it rather favors particularism and case-based approaches. To make the matter even more complicated, this generic capability is also present in the case of genetics and biotechnology by making life more malleable (Moor 2008, 35). What we witness today is the convergence of these two kinds of technology: it becomes easy to mediate life phenomena through datafication and computing. In fact, bioinformatics, as an applied and interdisciplinary science, is the best case for this conjunction because it puts computation at work to decipher and produce the "bricks" of life.

Computability qua logical malleability is a condition of possibility for infocentrism, and datafication is its majestic method. Datafication is happening worldwide at an exponential growth, similar to its complement, digitization. Unlike 
digitization, which is a process of converting analog information into binary code, "to datafy a phenomenon is to put it in a quantified format so it can be tabulated and analyzed” (Mayer-Schönberger and Cukier 2013, 78). Datafication is making possible infinite analyses in an "endless stream” (Mayer-Schönberger and Cukier 2013, 84) and anything could be turned into data, which in turn could be aggregated to reveal unexpected patterns and configurations (Mayer-Schönberger and Cukier 2013, 86). In this horizon of endless possibilities, the rise of infocentrism has just been a matter of time.

In a paper published in 1986 about hospital information systems, the term "infocentric" is used to describe the rapid development of health information systems (with the help and involvement of the medical personnel) and how they might be beneficial for the future of health care (O’Desky 1986). It seems that 30 years ago, the problem of responsibility within a plural, almost psychedelic, world was extremely pressing: "Everyone with computer responsibility must be vigilant to the kaleidoscopic modifications in requirements if the infocentric based systems are to be a propitious tool for the suppliers of healthcare services” (O’Desky 1986). Even today, this is sound advice.

According to an infocentric metaphysical doctrine - in ontology and information ethics - the concept of "data entity" is of paramount importance (Floridi and Sanders $2001,55)$. It sounds like a benign switch from anthropocentric or biocentric views to a more inclusive perspective; metaphysically, it is opening the way to a world composed and populated by multiple kinds of data entities. The shift is actually subtler, however. If granting differentiated moral status to data entities is not such a radical perspective, conceptualizing human persons as data entities certainly is. The net advantage of the infocentric view resides in its attempt to overcome the belief that only life phenomena are morally worthy. Infocentrism has now become a varied set of beliefs, sometimes inscribed in an ideology or a doctrine, which drive the continuous expansion of the digital technological lifeworld, instead of the macroethical framework Floridi intended it to be. We (started to) believe that anything, from simple to complex and from natural to artificial phenomena, can be construed as a data entity. Within Floridi's macroethics framework, the infocentric understanding of processes, things, and persons is sophisticated and worthy precisely because it addresses a key question: "What is good for an information entity and the infosphere in general?" The answer is provided by a minimalist theory of deserts: any information entity is recognised to be the centre of some basic ethical claims, which deserve recognition and should help to regulate the implementation of any information process involving it" (Floridi and Sanders 2002, 8). In sum even we, human persons, are information entities; life is a massive stream of logically malleable data, but where are the ethical claims and the deserved moral recognition? One instance of infocentrism could be seen in life sciences, where bioinformatics transforms biology into information science "contemporary biology works with vast bodies of data that the unaided human mind 
is incapable of processing effectively" (Griffiths and Stotz 2013, 145) - and reshapes life primitives (e.g., genes) into subjects of datafication.

At this point, we need to delve into another key aspect that could deepen our understanding: shared agency. Agency is perhaps the most significant (and essentially contested) concept in biomedical ethics, mainly because it makes possible the distinction between (autonomous) agents and (dependent) patients. It is also vital to determine agency to delegate responsibility and accountability for choices and actions. Mainstream bioethics identifies autonomy and agency as being something distinctive and uniquely human (O'Neill 2002, 6-7), which is a contestable assumption in highly technologized societies. Could agency be an exclusively human feature in our technological lifeworld? I believe it is not an exclusive feature of humans. I propose to understand agency as relational and shared between humans and different digital artifacts we encounter or rely on in apprehending our experiences.

Secondary and surrogate agency could be two alternative ways to grant artifacts the capacity of choice and goal orientation (Mitcham 2014, 13-22). In Mitcham's taxonomy, secondary agency emphasizes the political nature of artifacts. They could influence society because they are socially normative or nomologically deterministic, but this claim still assumes the ontological distinction between humans and objects. This ontological distinction has been refuted by the Actor Network Theory, another school of sociological thought that proposes that artifacts are proxy agents and are constitutive to actions. From simple calculus done with pocket calculators to highfrequency trading, genetic sequencing, and the International Space Station, actions are made possible, supported, delegated, or guided by digital artifacts. Without a computer, it seems impossible to set and achieve many of our aims. Intentionality, in a strong sense, is deeply connected with the idea of having consciousness, beliefs, and desires but is not a constraint for these categories of agency (Mitcham 2014). Instead, we should admit that many digital artifacts are oriented, have plans, and are purposive and are, thus, intentional (somehow like animals). In the case of computers and algorithms, they exhibit derived intentionality from their designers (Johnson 2006, apud Introna 2014, 34) and act upon the world as such. The more sophisticated the computing method, such as machine learning and deep learning centered on neural networks, is, the more complicated it becomes for us to understand "artificial intelligence" agency ${ }^{7}$. It is not difficult to agree on the fact that at least in two instances, (digital) artifacts exhibit agency: when they prove to be causally successful in combination with humans and when they are directly embedding human agency (Johnson and Noorman 2014, 148-52). Nonetheless, it is essential to not conflate

7 "No one really knows how the most advanced algorithms do what they do. That could be a problem." is a headline of an article published by MIT Technology Review on April 11, 2017: https://www. technologyreview.com/s/604087/the-dark-secret-at-the-heart-of-ai/ (accessed on May 13, 2017). 
moral agency and sociomaterial agency in the case of artifacts, but the former could be seen as a product of the latter.

The proposed concept of "shared agency" is similar to what Introna $(2014,40)$ called "co-constitutive agency" in humans and artifacts. Even in medical and healthcare settings, the human person is less and less the sole agent. In military or other combative industries, such as chess, go, and financial trading, algorithms will soon replace human intention, choice, and decision as they have already surpassed us in efficiency. The view of a single and unique (sometimes even under divine spell) category of agents - rational human beings using language to express intentions- is at odds with our technological lifeworld, which embraces us and sometimes even takes control of our lives.

These statements should not be read in a deterministic manner, but in a stoic one. How much of human intentions and deeds are exclusively human? And how many of them are shared between humans and their artifacts? It is not our task to count them but to make the second question valid by experiencing the kind of situation it addresses. The need for intelligent assistive technologies in health-care settings for challenging patients (Ienca et al. 2016; 2017) or the sophisticated algorithms that help identify patterns are two instances or types of events wherein we share agency with artificial kinds. These info-computational entities are constitutive to our technological lifeworld, even if they experience nothing of it.

\subsection{Conclusions}

This excursus was meant to engage the reader in a new way of thinking about vital assumptions in biomedical ethics. For this, I presented an alternative view regarding our digital tools and environments of human experience, which is opposite to the neutrality and functionalist views. Computers, algorithms, neural networks, and data sets are not neutral instruments operating only as a result of our agency, but rather are digital artifacts that present not only affordances but also shape the human thought and action. The liberal-instrumental view should be overcome if we want to understand the realities in health-care settings, wherein agents, patients, and digital artifacts form a joint apparatus (Introna 2014). The causal efficacy in the malleability of life that computers and algorithms display is a strong rationale for changing our moral view and explanatory vocabulary so as to accommodate shared agency. Obviously, this does not imply the conflation of intentionality and subjectivity in making choices but rather the conceptual broadening about how and to whom to designate responsibility in health-care acts. As I claimed before, it is not a deterministic view - we are not trapped in a technological lifeworld without any control or choice -but more of a social constructivist stance by which artifacts have "interpretative flexibility" in interacting with us. Simply put, they are active social constructions, not inert objects around us (Brey 2005, 67-9). 
As I stated before, the infocentric doctrine is convergent with a soft social constructivism. When the efficacious treatment of information is at stake, we are compelled to see even human persons as data entities. Remaining just an economic and social ideology, infocentrism could be a threat to our survival if ethical considerations are left out. On the other hand, infocentrism understood as a comprehensive approach to life and to the technological lifeworld can help us mediate between natural and artificial entities. Mediation is a process of integration and adaptation to a complex system made of organisms, information, computational mechanisms, cognition, and semantic meanings. Artificial and natural phenomena are a continuum that could not be divided into different realms. Datafication is both a material process of creating informational representations of human features and activities, as well as an intellectual approach to the complexities of nature and life. Its reductionist method should be balanced by the human social meanings instilled in the process.

The European Data Protection Supervisor, an independent body of the European Union, has a strategy for the ethical dimension beyond the legal rules regulating data protection ${ }^{8}$, a strategy that is based on an opinion document from 2015 called “Towards a new digital ethics" (European Data Protection Supervisor 2015). I believe this official opinion is a paradigmatic example for the "traditional" view in bioethics, which opposes persons and their agency to artifacts and systems seen as inert functional tools. Liberal-instrumental, as well as being reductionist, this utopian view is driven by the belief in human uniqueness and hence by our ontological and therefore moral dissimilarity. The author(s) of this paper put "human dignity" at the core, thus producing an individualistic and humanistic ethical proposal that is admirable and optimistic, but misguided. A moral upgrade is needed for not only the right to privacy but also the assumptions of this ethical approach. For example, one of the suppositions of this document is that "technology is controlled by humans" (European Data Protection Supervisor 2015, 14) or at least through the decisions we make about its development. While the proposals target real problems - such as the opacity and secrecy around data absorption practices, the need for instillation of privacy values directly into digital design, and so on (European Data Protection Supervisor 2015, 10) - the idea of citizen consent and control over data use as a policy solution is neither complete nor effectual. This grounding paper is an example of aprioristic thinking founded in a deontologist concept, i.e., human dignity, where agency is idealistically solely human. Although it takes into account the pervasiveness of datafication and the emergent powers of algorithms fed by Big Data, it does not construe them in their right: as forming with us a "joint apparatus”. In Moor's words, this is an attempt to fill a policy vacuum without clarifying conceptual muddles.

8 More information about the strategy could be found here: https:/edps.europa.eu/data-protection/ our-work/ethics_en (accessed on 5 June 2017). 
Our technological lifeworld has become an info-computational media populated by data and algorithms, an artificial environment for life and shared experiences. The previous sketch of three alternative assumptions for bioethics - it is hardly possible to substantiate ethical guidelines or an idea of normativity in an aprioristic manner; moral status is a function of data entities, not something solely human; agency is plural and thus is shared or sometimes delegated - tried to chart a proposal for a posthuman bioethics. Posthuman is perhaps not the best expression available, but it covers the idea of a shift from a world centered on self-contained and exclusively human agency to a more comprehensive and relational way of thinking. The "posthuman" label should be understood as a rebuttal of biocentrism and anthropocentrism by moving closer to conceptions we encounter in population ethics or in discourse about biosocial and technical systems. Posthuman bioethics is "environmentalist" without losing the humanistic stance. The question regarding how suitable an infocentric bioethics is in practice remains to be settled. The moral principles in bioethics could be reconceived as relying on these new assumptions, in a postindividualistic manner that accepts formal primacy of causal digital artifacts in affording actions in a world of ambient algorithmic intelligence.

\section{References}

Arras, John. 2016. “Theory and Bioethics.” In The Stanford Encyclopedia of Philosophy (Winter 2016 Edition), Edward N. Zalta (ed.). Metaphysics Research Lab, Stanford University. https://plato. stanford.edu/archives/win2016/entries/theory-bioethics/.

Brey, Philip. 2005. "Artifacts as Social Agents." In Inside the Politics of Technology: Agency and Normativity in the Co-Production of Technology and Society, edited by Hans Harbers, 61-84. Amsterdam, The Netherlands: Amsterdam University Press.

Dodig-Crnkovic, Gordana. 2004. "On the Importance of Teaching Professional Ethics to Computer Science Students, Computing and Philosophy." In Computing and Philosophy E-CAP 2004. Associated International Academic Publishers.

European Data Protection Supervisor. 2015. “Towards a New Digital Ethics. Data, Dignity and Technology.” Opinion 4/2015. Brussels: European Data Protection Supervisor. https://edps. europa.eu/data-protection/our-work/publications/opinions/towards-new-digital-ethics-datadignity-and_en.

Feschotte, Cédric. 2010. “Virology: Bornavirus Enters the Genome.” Nature 463 (7277): 39-40.

Floridi, Luciano. 2014. The Fourth Revolution: How the Infosphere Is Reshaping Human Reality. Oxford University Press.

Floridi, Luciano, and Jeff W. Sanders. 2001. "Artificial Evil and the Foundation of Computer Ethics.” Ethics and Information Technology 3 (1): 55-66.

Floridi, Luciano, and Jeff W. Sanders. 2002. "Mapping the Foundationalist Debate in Computer Ethics." Ethics and Information Technology 4 (1): 1-9.

Griffiths, Paul, and Karola Stotz. 2013. Genetics and Philosophy: An Introduction. Cambridge, UK ; New York: Cambridge University Press.

Heidegger, Martin. 1962. Being and Time. Translated by John Macquarrie and Edward S Robinson. Oxford, UK: Blackwell Publishers. 
Horie, Masayuki, Tomoyuki Honda, Yoshiyuki Suzuki, Yuki Kobayashi, Takuji Daito, Tatsuo Oshida, Kazuyoshi Ikuta, Patric Jern, Takashi Gojobori, John M. Coffin, and Keizo Tomonaga. 2010. “Endogenous Non-Retroviral RNA Virus Elements in Mammalian Genomes." Nature 463 (7277): 84-87.

Ienca, Marcello, Fabrice Jotterand, Bernice Elger, Maurizio Caon, Alessandro Scoccia Pappagallo, Reto W. Kressig, and Tenzin Wangmo. 2017. “Intelligent Assistive Technology for Alzheimer's Disease and Other Dementias: A Systematic Review.” Journal of Alzheimer's Disease 56 (4): 1301-40.

Ienca, Marcello, Fabrice Jotterand, Constantin Vică, and Bernice Elger. 2016. "Social and Assistive Robotics in Dementia Care: Ethical Recommendations for Research and Practice." International Journal of Social Robotics 8 (4): 565-573.

Ihde, Don. 1990. Technology and the Lifeworld: From Garden to Earth. Indiana University Press.

Introna, Lucas D. 2014. “Towards a Post-Human Intra-Actional Account of Socio-Technical Agency (and Morality)." In The Moral Status of Technical Artefacts, edited by Peter Kroes and Peter-Paul Verbeek, 31-53. Philosophy of Engineering and Technology 17. Springer Netherlands.

Johnson, Deborah G., and Merel Noorman. 2014. "Artefactual Agency and Artefactual Moral Agency.” In The Moral Status of Technical Artefacts, edited by Peter Kroes and Peter-Paul Verbeek, 143-58. Philosophy of Engineering and Technology 17. Springer Netherlands.

Mayer-Schönberger, Viktor, and Kenneth Cukier. 2013. Big Data: A Revolution That Will Transform How We Live, Work, and Think. Houghton Mifflin Harcourt.

McLuhan, Marshall. 1994. Understanding Media: The Extensions of Man. Edited by Lewis H. Lapham. Reprint edition. Cambridge, Mass: The MIT Press.

Mitcham, Carl. 2014. "Agency in Humans and in Artifacts: A Contested Discourse.” In The Moral Status of Technical Artefacts, edited by Peter Kroes and Peter-Paul Verbeek, 11-29. Philosophy of Engineering and Technology 17. Springer Netherlands.

Moor, James H. 1985. “What Is Computer Ethics?” Metaphilosophy 16 (4): 266-75.

Moor, James H. 1999. "Just Consequentialism and Computing." Ethics and Information Technology 1 (1): $61-65$

Moor, James H. 2008. “Why We Need Better Ethics for Emerging Technologies.” In Information Technology and Moral Philosophy, edited by van den Hoven, Jeroen and Weckert, John. Cambridge Studies in Philosophy and Public Policy. Cambridge University Press.

O’Desky, Robert I. 1986. “An Infocentric View of the Hospital Information System.” Healthcare Computing \& Communications 3 (1): 44-46.

O’Neill, Onora. 2002. Autonomy and Trust in Bioethics. Cambridge, UK: Cambridge University Press.

Opriş, David, Sebastian Pintea, Azucena García-Palacios, Cristina Botella, Ştefan Szamosközi, and Daniel David. 2012. "Virtual Reality Exposure Therapy in Anxiety Disorders: A Quantitative Meta-Analysis." Depression and Anxiety 29 (2): 85-93.

Swan, Melanie. 2013. "The Quantified Self: Fundamental Disruption in Big Data Science and Biological Discovery.” Big Data 1 (2): 85-99. doi:10.1089/big.2012.0002.

Voinea, Cristina. 2016. “Guvernare fără guvernanți: politica prin algoritmi și Big Data.” Revista de filosofie LXIII (5): 583-95.

Wolpaw, Jonathan R., Niels Birbaumer, Dennis J. McFarland, Gert Pfurtscheller, and Theresa M. Vaughan. 2002. "Brain-Computer Interfaces for Communication and Control." Clinical Neurophysiology 113 (6): 767-91.

Woolley, Samuel C., and Philip N. Howard. 2016. "Political Communication, Computational Propaganda, and Autonomous Agents - Introduction.” International Journal of Communication 10 (0): 9.

Zittrain, Jonathan. 2008. The Future of the Internet and How to Stop It. Yale University Press. https:// dash.harvard.edu/handle/1/4455262. 
Zylinska, Joanna. 2009. Bioethics in the Age of New Media. 1st edition. Cambridge, Mass: The MIT Press. 